\title{
The influence of feed and herd on fatty acid composition in 3 dairy breeds (Danish Holstein, Danish Jersey, and Swedish Red)
}

\author{
N. A. Poulsen, ${ }^{\star 1}$ F. Gustavsson, $†$ M. Glantz,† M. Paulsson, † L. B. Larsen, ${ }^{\star}$ and M. K. Larsen* \\ *Department of Food Science, Aarhus University, DK-8830 Tjele, Denmark \\ †Department of Food Technology, Engineering and Nutrition, Lund University, SE-221 00 Lund, Sweden
}

\begin{abstract}
The composition of milk fat from dairy cows is related to both genetic and environmental factors. Here, the effect of feed and herd was examined in 3 Scandinavian breeds, namely Danish Holstein-Friesian (DH), Danish Jersey (DJ), and Swedish Red (SR). In total, milk samples from 1,298 cows kept in indoor housing systems were collected from 61 conventional dairy herds in Denmark and Sweden. The fatty acid (FA) composition of milk was determined by gas chromatography and the content of $\alpha$-tocopherol by HPLC. Based on the 17 individual FA determined, distinct FA profiles were observed for all breeds using univariate and multivariate statistics. The DJ cows were characterized by higher levels of saturated short-chain FA; in contrast, DH cows had higher content of unsaturated C18 FA, whereas higher levels of primarily C14:0, C14:1, C18:1 cis-9, and C18:3n-3 were evident in SR cows. This variation in milk fat composition across breeds was further reflected in different desaturase indices, which were generally higher in SR cows. In addition, $\alpha$-tocopherol differed significantly among breeds, with DJ cows having the highest content. Herd-specific feeding plans were collected, and different feed items were separated into 4 broad feed categories, including grass products, maize silage, grain, and concentrate. The pronounced differences in overall feed composition among breeds were, to a large extent, due to regional differences between countries, with SR receiving higher levels of grain and grass silage compared with the Danish breeds. Within breeds, differences in feeding regimens among herds were furthermore higher in SR. Significant correlations between feed category and individual FA were observed in all breeds. Furthermore, variance components were estimated and used to determine the proportion of phenotypic variation that could be explained by herd. The herd effect for individual FA was generally lower for DH compared with the 2 other breeds. In addition,
\end{abstract}

Received June 8, 2012.

Accepted June 21, 2012

${ }^{1}$ Corresponding author: Nina.Poulsen@agrsci.dk very low herd effects were shown for C14:1 and C16:1 in all breeds, suggesting that the content of these FA is mainly genetically regulated.

Key words: breed difference, indoor feeding, herd effect, $\alpha$-tocopherol

\section{INTRODUCTION}

From a nutritional point of view, it is desirable to increase the level of unsaturated FA in milk, which, in turn, depends on the interplay between the feed composition, rumen metabolism, and mammary synthesis. The nutritional value of milk is related to essential FA (linoleic and $\alpha$-linolenic acid), as well as specific FA showing beneficial health effects, such as conjugated linoleic acid (CLA) and n-3 FA (German and Dillard, 2006). An increase in healthy FA in human food sources and, likewise, a decrease in FA with negative effect on human health (in particular, palmitic acid) is, thus, desirable (Mensink et al., 2003; Givens, 2010).

Based on genetic background or breed-specific management traditions, or both, milk from different bovine breeds holds distinct FA profiles (Lawless et al., 1999; Carroll et al., 2006). The dietary effect on FA composition of bovine milk is closely linked to the balance between feed composition, fermentation in the rumen, and metabolic processes in the mammary gland. Thus, milk fat consists partly of preformed FA taken up directly from feed, from body mobilization, as well as FA synthesized de novo in the mammary gland from acetate and BHBA, originating from microbial fermentation of polysaccharides in the rumen. The key regulatory enzymes of the mammary de novo milk fat synthesis are acetate CoA carboxylase and FA synthase. Whereas C4:0 to C14:0 are solely generated through the de novo synthesis in the mammary gland, varying amounts of C16:0 are synthesized de novo (Grummer, 1991; Sejrsen et al., 2007). In contrast, long-chain FA in milk originate almost exclusively from the feed, but may be modified considerably in the rumen, as well as in the mammary gland. Within the rumen, isomerization and hydrogenation depend on the FA content in the feed, but they also relate to feed-derived starch and fiber 
content, which affect rumen fermentation and thereby also play a role in the FA synthesis. In the mammary gland, the FA undergo desaturation that converts, for example, C18:1 trans-11 (formed by biohydrogenation of both linoleic and linolenic acid in the rumen) to CLA cis-9,trans-11 and C18:0 to C18:1 cis-9, and thereby increases the level of MUFA excreted into the milk (Sejrsen et al., 2007). Thus, PUFA of dietary origin are highly modified before being secreted into the milk and biohydrogenation in the rumen of, for example, linoleic acid and linolenic acid has been reported to be as high as 70 to $95 \%$ and 85 to $100 \%$, respectively, resulting in a low recovery of feed FA in milk (Doreau and Ferlay, 1994).

Increased amounts of pasture in the diet of dairy cows raise the content of particularly CLA, as well as C18:1 trans-11 in milk fat, whereas the positive effect on the content of $\mathrm{C} 18: 3 \mathrm{n}-3$ is only observed up to a certain extent (Butler et al., 2008; Slots et al., 2009; Larsen et al., 2010). Likewise, greater amounts of shortchain FA at the expense of medium-chain FA in the summer also indicate that fresh grass can contribute to a healthier FA intake by reducing the unfavorable medium-chain FA, which have been suggested to be associated with higher blood cholesterol levels (Maijala, 2000). Generally, a lower n-3-to-n-6 ratio in milk, which has been ascribed to a decrease in, particularly, the pasture-based feed components, has given rise to some concern (Simopoulos, 2002), due to the beneficial cardiovascular effects of $\alpha$-linolenic acid (Albert et al., 2005; Djoussé et al., 2005).

The association between feeding regimens and FA composition is, thus, well established, but although a practice has long been in place for manipulating FA composition through feed, the contribution of genetic variation to the phenotypic variation is also substantial, providing good opportunities for genetically modifying the FA profile through selective breeding. Whereas the heritability estimates of individual FA vary (Karijord et al., 1982; Stoop et al., 2008), short- and mediumchain FA generally have higher heritabilities, ranging from 0.42 to 0.71 (Stoop et al., 2008). Likewise, using product-to-substrate ratio as a proxy for desaturase activity, high heritability estimates $(0.23-0.47)$ have also been found for desaturase indices (Schennink et al., 2009; Stoop et al., 2009), and this suggests that genetic parameters play an important role in milk fat composition.

The level of antioxidants in milk plays an important role in relation to the oxidative stability of milk and has been shown to be affected by different feed components. Thus, a higher level of $\alpha$-tocopherol and $\beta$-carotene has been related to high pasture proportions in the feed (Havemose et al., 2004). Thereby, higher levels of antioxidants are correlated with higher levels of unsaturated FA (Slots et al., 2009), probably due to higher levels of those vitamins in pasture in general (Havemose et al., 2004).

In this study, we integrated milk FA profiles, milk $\alpha$-tocopherol content, and feed data from 3 breeds, namely, Danish Holstein-Friesian (DH), Danish Jersey (DJ), and Swedish Red (SR). Each breed showed distinct milk FA profiles, despite large individual variation within breeds. Based on different genetic background, we assumed that the individual breeds showed different associations between feed and milk composition and that regional differences in management practice between countries would affect this pattern as well. Thus, from herd-specific feeding plans, 4 feed categories were used to assign the effect of feeding regimens on milk FA composition and milk $\alpha$-tocopherol content. Also, herd effects for individual FA as well as $\alpha$-tocopherol were examined, providing a profound insight into how the herd effects and different feeding regimens in the 3 breeds affect the overall composition.

\section{MATERIALS AND METHODS}

\section{Milk Sampling and Herd Feeding Regimens}

As part of the Danish-Swedish Milk Genomics Initiative, morning milk was collected from 1,298 individual dairy cows. The overall experimental strategy underlying this study was to minimize potential sources of environmental variation and maximize the level of genetic variation in the sample population. As a result, the pedigree of the selected animals was designed to include as unrelated animals as possible. In Denmark, milk samples were collected from $456 \mathrm{DH}$ cows (20 dairy herds, October-December 2009) and from 435 DJ cows (22 dairy herds, February-April 2010). All DJ and DH herds were located between the 55.0 and $57.4^{\circ}$ latitudes. Likewise, 407 milk samples were collected in Sweden from SR cows (19 herds, October 2010-April 2011). All Swedish herds were located in Southern Sweden, between the 56.5 and $58.3^{\circ}$ latitudes. Sampling was carried out at one morning milking at conventional (nonorganic) herds during the indoor period. The cows were primarily milked twice daily and only rarely 3 times. Milk yield at the particular milking was recorded and representative milk samples of at least $0.5 \mathrm{~L}$ were placed on ice during transport to the laboratory. The Swedish milk samples had a 24-h cooling period due to transport to the laboratory in Denmark, but were otherwise treated the same way.

Herd-specific feeding plans were provided by the dairy farmers and relative feed proportions of grain, maize silage, grass products (mainly grass silage, but 
also minor amounts of whole crop silage, hay, and straw), and concentrate were calculated. These broad feed categories should cover different feed sources with potential influence on the FA composition. For SR, sufficient feed information was not provided for 3 of the herds, and these were excluded from the feed analyses.

\section{Milk Analyses}

Fat and protein contents were determined on fresh whole milk samples by using a MilkoScan FT2 apparatus (Foss Electric A/S, Hillerød, Denmark). The whole milk samples were frozen and stored at $-20^{\circ} \mathrm{C}$ until analysis of $\alpha$-tocopherol. Cream was separated from skim milk by centrifugation $(2,643 \times g$ for $30 \mathrm{~min}$ at $\left.4^{\circ} \mathrm{C}\right)$. Hereafter, the cream samples were stored at $-20^{\circ} \mathrm{C}$ until analysis of FA composition using GC, essentially as described by Larsen et al. (2011).

Peak areas for individual FA were calculated after GC separation. Fatty acids were identified and quantified via the use of external standards [Supelco 37 component FA methyl ester (FAME) mix, Supelco Inc., Bellefonte, PA and GLC 469 methyl ester standard, Nu-Chek Prep Inc., Elysian, MN] and expressed as weight proportion of total identified FA. Only FA present at a minimum of $5 \mathrm{~g} / \mathrm{kg}$ of FA (average) were included. The C4:0 peak was not always separated and this FA was, therefore, not included in the study. Individual C18:1 trans isomers were not fully separated, and the peak assigned as C18:1 trans-11 was a mixture of trans-10 and trans-11 isomers. Desaturase indices were calculated as the ratio between product and sum of product and substrate and used as a proxy for $\Delta^{9}$-desaturase activity for the following pairs of product and substrate: C14:1 cis-9 and C14:0, C16:1 cis-9 and C16:0, C18:1 cis-9 and C18:0, and C18:2 cis-9,trans-11 and 18:1 trans-11.

For $\alpha$-tocopherol determination, the protocol outlined in Havemose et al. (2004) was used with separation and quantification on an HPLC system (HP 1100; HewlettPackard Co., Santa Clara, CA) equipped with a Zorbax RX SIL column $(4.6 \times 15 \mathrm{~mm}, 5-\mu \mathrm{m}$ i.d. $)$. The results were presented as $\alpha$-tocopherol content in milk fat.

\section{Statistical Analysis}

Multivariate data analysis was carried out by the use of Simca-P + version 13 (Umetrics AB, Umeå, Sweden). Initial principal component (PC) analysis of FA composition showed no clear grouping of breeds, and to investigate to which extent it was possible to separate breeds according to their milk FA composition, data were analyzed by orthogonal partial least squares discriminant analysis (OPLS-DA). One-way univariate
ANOVA provided breed differences in feed and milk composition. Within each breed, a general linear model for herd effect was used in the analysis:

$$
\mathrm{Y}_{\mathrm{i}}=\mu+\operatorname{herd}_{\mathrm{i}}+\mathrm{e}_{\mathrm{i}}
$$

where $Y_{i}$ is the dependent variable, $\mu$ is the general mean, herd ${ }_{\mathrm{i}}$ is herd as a fixed effect $(\mathrm{i}=1,2, \ldots, 22)$, and $e_{i}$ is the residual error term. Furthermore, univariate analyses were performed to estimate the proportion of variation due to herd effects (\%herd):

$$
\text { \%herd }=\left[\sigma_{\mathrm{h}}^{2} /\left(\sigma_{\mathrm{h}}^{2}+\sigma_{\mathrm{e}}^{2}\right)\right] \times 100 \%,
$$

where $\sigma_{\mathrm{h}}^{2}$ is the herd variation and $\sigma_{\mathrm{e}}^{2}$ is the residual variation. With the approximation that cows from the same herd had identical feeding regimens, correlations between the feed categories and herd means of individual FA and related traits were determined using Pearson correlation tests. All tests were performed using R software (version 2.10.0; http://www.r-project. org).

\section{RESULTS}

\section{Milk, $\alpha$-Tocopherol and FA Profiles from $\mathrm{DH}$, $D J$, and $S R$}

Sampling information on milk fat and protein contents as well as average feed composition according to categories for each breed is presented in Table 1. Parity was very similar among breeds, whereas lactation stage varied more within SR than within the 2 Danish breeds. Overall, the protein content was highest in milk from DJ and lowest in milk from $\mathrm{DH}$, whereas the fat content was highest in milk from DJ, but did not differ between DH and SR.

Table 2 presents the FA composition and the content of $\alpha$-tocopherol in milk fat for all breeds as means with standard deviations. The most abundant FA in milk from all breeds were palmitic $(\mathrm{C} 16: 0)$ and oleic acid (C18:1 cis-9), which are responsible for about $50 \%$ of the FA content. Most FA were significantly different among breeds, but with less pronounced breed differences in $\mathrm{C} 13: 0, \mathrm{C} 16: 1, \mathrm{C} 17,18: 2$ cis-9,12, and $\mathrm{C} 18: 3$ cis-9,12,15 (C18:3n-3). The indices reflecting desaturation of myristic (C14:0), palmitic, stearic (C18:0), and vaccenic (C18:1 trans-11) acids in the mammary gland were also significantly different among breeds. Swedish Reds had the highest C14, C18, and CLA indices, whereas the $\mathrm{C} 16$ index was highest in $\mathrm{DH}$. The amount of $\alpha$-tocopherol was found to be highest in milk from DJ and lowest in DH. 
Table 1. Sampling information in relation to number of samples and herds included ${ }^{1}$

\begin{tabular}{lccc}
\hline Variable & DH & DJ & SR \\
\hline Number of samples & 456 & 435 & 407 \\
Number of herds & 20 & 22 & $19(16)^{2}$ \\
Parity & $1.73(0.77)^{\mathrm{a}}$ & $1.73(0.78)^{\mathrm{a}}$ & $1.78(0.77)^{\mathrm{a}}$ \\
Lactation stage $(\mathrm{wk})$ & $25.65(3.07)^{\mathrm{a}}$ & $26.56(3.26)^{\mathrm{ab}}$ & $27.10(11.05)^{\mathrm{b}}$ \\
Actual milk yield $(\mathrm{kg})$ & $14.55(3.91)^{\mathrm{a}}$ & $10.10(2.64)^{\mathrm{b}}$ & $13.68(4.50)^{\mathrm{c}}$ \\
Fat percentage $(\mathrm{g} / 100 \mathrm{~g})$ & $4.02(0.82)^{\mathrm{a}}$ & $5.99(0.86)^{\mathrm{b}}$ & $4.13(0.86)^{\mathrm{a}}$ \\
Protein percentage $(\mathrm{g} / 100 \mathrm{~g})$ & $3.44(0.26)^{\mathrm{a}}$ & $4.30(0.32)^{\mathrm{b}}$ & $3.66(0.36)^{\mathrm{c}}$ \\
Proportion of grass products & $0.21(0.05)^{\mathrm{a}}$ & $0.20(0.06)^{\mathrm{a}}$ & $0.37(0.14)^{\mathrm{b}}$ \\
Proportion of maize silage & $0.38(0.06)^{\mathrm{a}}$ & $0.34(0.06)^{\mathrm{a}}$ & $0.07(0.13)^{\mathrm{b}}$ \\
Proportion of grain & $0.07(0.06)^{\mathrm{a}}$ & $0.08(0.07)^{\mathrm{a}}$ & $0.20(0.11)^{\mathrm{b}}$ \\
Proportion of concentrate & $0.34(0.07)^{\mathrm{a}}$ & $0.39(0.06)^{\mathrm{a}}$ & $0.36(0.15)^{\mathrm{a}}$ \\
\hline
\end{tabular}

${ }^{\mathrm{a}-\mathrm{C}}$ Means within a row followed by different superscript letters indicate significant breed differences $(P<0.05)$. ${ }^{1}$ Average parity number and stage of lactations as well as overall milk and feed composition for Danish Holstein-Friesians (DH), Danish Jerseys (DJ), and Swedish Reds (SR) are presented as the mean and SD (in parentheses).

${ }^{2}$ Feed information was only available for 16 SR herds.

Despite large individual variation within breeds, the OPLS-DA score plot demonstrated that breeds could be separated based on their milk FA compositions (Figure 1). The first PC separated SR and DJ, whereas the second PC separated DH from the other 2 breeds. The overall cumulated percent of variation predicted by cross-validation of the model was 0.61 . The loading plot showed that milk samples from DJ and SR were

Table 2. Fatty acids and related traits in Danish Holstein-Friesians (DH), Danish Jerseys (DJ), and Swedish Reds (SR) presented as mean and $\mathrm{SD}$ (FA are given in $\mathrm{g} / \mathrm{kg}$ of $\mathrm{FA}$ )

\begin{tabular}{|c|c|c|c|c|c|c|}
\hline \multirow[b]{2}{*}{ FA } & \multicolumn{2}{|c|}{$\mathrm{DH}$} & \multicolumn{2}{|c|}{ DJ } & \multicolumn{2}{|c|}{$\mathrm{SR}$} \\
\hline & Mean & $\mathrm{SD}$ & Mean & $\mathrm{SD}$ & Mean & $\mathrm{SD}$ \\
\hline C6:0 & $26.83^{\mathrm{a}}$ & 3.44 & $27.94^{\mathrm{b}}$ & 2.99 & $24.58^{\mathrm{c}}$ & 3.70 \\
\hline $\mathrm{C} 8: 0$ & $14.62^{\mathrm{a}}$ & 2.26 & $16.15^{\mathrm{b}}$ & 1.88 & $12.92^{\mathrm{c}}$ & 2.05 \\
\hline C10:0 & $31.52^{\mathrm{a}}$ & 5.69 & $35.61^{\mathrm{b}}$ & 4.85 & $29.78^{\mathrm{c}}$ & 5.45 \\
\hline C12:0 & $35.62^{\mathrm{a}}$ & 6.56 & $40.56^{\mathrm{b}}$ & 6.11 & $37.09^{c}$ & 7.03 \\
\hline C13:0 & $1.00^{\mathrm{a}}$ & 0.31 & $1.38^{\mathrm{b}}$ & 0.46 & $1.06^{\mathrm{c}}$ & 0.30 \\
\hline C14:0 & $112.34^{\mathrm{a}}$ & 12.90 & $105.80^{\mathrm{b}}$ & 8.99 & $117.32^{\mathrm{c}}$ & 12.52 \\
\hline C14:1 & $9.73^{\mathrm{a}}$ & 2.73 & $8.32^{\mathrm{b}}$ & 1.71 & $11.01^{\mathrm{c}}$ & 2.85 \\
\hline C15:0 & $10.96^{\mathrm{a}}$ & 1.94 & $11.91^{\mathrm{b}}$ & 2.06 & $9.28^{\mathrm{c}}$ & 1.48 \\
\hline C16:0 & $289.13^{\mathrm{a}}$ & 33.41 & $303.72^{\mathrm{b}}$ & 33.14 & $324.83^{\mathrm{c}}$ & 34.71 \\
\hline C16:1 & $15.02^{\mathrm{a}}$ & 3.82 & $13.80^{\mathrm{b}}$ & 3.04 & $14.13^{\mathrm{b}}$ & 3.46 \\
\hline C17 & $5.27^{\mathrm{a}}$ & 1.47 & $5.20^{\mathrm{a}}$ & 1.08 & $3.97^{\mathrm{b}}$ & 0.56 \\
\hline C18:0 & $104.50^{\mathrm{a}}$ & 20.37 & $116.78^{\mathrm{b}}$ & 16.98 & $89.31^{\mathrm{c}}$ & 16.97 \\
\hline $\mathrm{C} 18: 1$ cis-9 & $200.75^{\mathrm{a}}$ & 29.20 & $164.23^{\mathrm{b}}$ & 20.41 & $181.51^{\mathrm{c}}$ & 27.05 \\
\hline $\mathrm{C} 18: 1$ trans $-11^{1}$ & $16.84^{\mathrm{a}}$ & 5.20 & $15.05^{\mathrm{b}}$ & 4.04 & $10.70^{\mathrm{c}}$ & 3.71 \\
\hline $\mathrm{C} 18: 2$ cis $-9,12$ & $16.94^{\mathrm{a}}$ & 2.86 & $15.18^{\mathrm{b}}$ & 3.02 & $14.85^{\mathrm{b}}$ & 3.16 \\
\hline C18:2 cis-9,trans-11 & $6.28^{\mathrm{a}}$ & 1.56 & $4.49^{\mathrm{b}}$ & 1.15 & $4.97^{\mathrm{c}}$ & 1.62 \\
\hline $\mathrm{C} 18: 3$ cis- $9,12,15$ & $4.93^{\mathrm{a}}$ & 1.01 & $4.07^{\mathrm{b}}$ & 0.75 & $4.78^{\mathrm{a}}$ & 1.19 \\
\hline $\mathrm{C} 6-\mathrm{C} 10$ & $72.97^{\mathrm{a}}$ & 10.78 & $79.70^{\mathrm{b}}$ & 8.78 & $67.29^{\mathrm{c}}$ & 10.21 \\
\hline $\mathrm{C} 12-\mathrm{C} 14 \mathrm{wt}$ & $148.95^{\mathrm{a}}$ & 18.77 & $147.74^{\mathrm{a}}$ & 14.33 & $155.48^{\mathrm{b}}$ & 18.57 \\
\hline Ratio n-3:n-6 ${ }^{2}(\%)$ & $29.33^{\mathrm{a}}$ & 0.05 & $27.35^{\mathrm{b}}$ & 0.05 & $33.04^{\mathrm{c}}$ & 0.09 \\
\hline C14 index ${ }^{3}(\%)$ & $7.95^{\mathrm{a}}$ & 1.95 & $7.28^{\mathrm{b}}$ & 1.33 & $8.58^{c}$ & 2.02 \\
\hline C16 index ${ }^{4}(\%)$ & $4.93^{\mathrm{a}}$ & 1.06 & $4.35^{\mathrm{b}}$ & 0.81 & $4.17^{\mathrm{c}}$ & 0.92 \\
\hline C18 index ${ }^{5}(\%)$ & $65.80^{\mathrm{a}}$ & 4.30 & $58.49^{\mathrm{b}}$ & 3.25 & $67.05^{\mathrm{c}}$ & 4.29 \\
\hline CLA index ${ }^{6}(\%)$ & $27.78^{\mathrm{a}}$ & 6.02 & $23.23^{\mathrm{b}}$ & 3.29 & $31.90^{\mathrm{c}}$ & 4.50 \\
\hline$\alpha$-Tocopherol ( $\mu \mathrm{g} / \mathrm{g}$ of fat) & $20.30^{\mathrm{a}}$ & 5.37 & $22.80^{\mathrm{b}}$ & 6.15 & $21.64^{\mathrm{c}}$ & 6.11 \\
\hline
\end{tabular}

${ }^{\mathrm{a}-c}$ Means within a row followed by different superscript letters indicate significant differences among breeds $(P<0.05)$.

${ }^{1} \mathrm{C} 18: 1$ trans $-11=$ mixture of $\mathrm{C} 18: 1$ trans- 11 and $\mathrm{C} 18: 1$ trans -10 .

${ }^{2}$ Ratio n-3:n-6 $=(\mathrm{C} 18: 3$ cis- $9,12,15 / \mathrm{C} 18: 2$ cis-9,12 $) \times 100$.

${ }^{3} \mathrm{C} 14$ index $=\mathrm{C} 14: 1 /(\mathrm{C} 14: 1+\mathrm{C} 14: 0) \times 100$.

${ }^{4} \mathrm{C} 16$ index $=\mathrm{C} 16: 1 /(\mathrm{C} 16: 1+\mathrm{C} 16: 0) \times 100$.

${ }^{5} \mathrm{C} 18$ index $=\mathrm{C} 18: 1$ cis-9/(C18:1 cis-9 $\left.+\mathrm{C} 18: 0\right) \times 100$.

${ }^{6}$ Conjugated linoleic acid $(\mathrm{CLA})$ index $=\mathrm{C} 18: 2$ cis-9,trans-11/(CLA cis-9,trans $-11+\mathrm{C} 18: 1$ trans-11) $\times 100$. 
separated by the first PC, based primarily on higher contents of $\mathrm{C} 6: 0$ to $\mathrm{C} 12: 0, \mathrm{C} 13: 0$ to $\mathrm{C} 17: 0$, and $\mathrm{C} 18: 0$ in milk fat from DJ and higher contents of C14:0, C14:1, C18:1 cis-9, and C18:3n-3 in milk fat from SR. Danish Holstein-Friesians were separated from DJ and SR by the second PC based on higher contents of all unsaturated C18 FA and lower content of particular C12:0, C13:0, and C16:0 in milk fat.

\section{Herd Variance and Feed Imprints}

The feeding regimens were very similar in the Danish breeds, whereas Swedish dairy farmers generally provided higher levels of grain and grass products to their cows but a lower level of maize silage (Table 1). The feed variation among herds was larger for SR, as shown by the higher standard deviations for the feed categories. Furthermore, the influence of different feed categories on FA composition in individual breeds revealed several significant correlations (Figure 2). Grass products showed a significant, negative correlation with linoleic acid $(\mathrm{C} 18: 2$ cis-9,12) in DH and DJ, which was further reflected in the positive, significant correlations with the n-3:n-6 ratio also observed in these breeds. In SR, the content of grass products was significantly, negatively correlated with $\mathrm{C} 6: 0$ to $\mathrm{C} 14: 0$ and positively correlated with $\alpha$-tocopherol. In contrast, the amount of maize silage significantly affected only the FA composition in $\mathrm{DH}$, showing a negative correlation with C16:0 and C16:1 and a positive correlation with C18:1 trans-11 and CLA cis-9,trans-11. Apart from the forage components, grain was shown to affect the level of C18:0 significantly in a positive manner in SR and C18:3n-3 and, thus, the n-3:n-6 ratio negatively in DJ. Lastly, several significant correlations were revealed between concentrate and specific FA. These included significant, positive correlations with $\mathrm{C} 18: 1$ trans-11 (DJ and SR) and C18:1 cis-9 (DH and SR) as well as negative correlations with $n-3: n-6$ ratio (SR) and with $\alpha$-tocopherol in both DJ and SR.

Generally, the proportion of variance explained by herd differed among breeds and was considerably lower for DH (4-26\%) than for the other 2 breeds (9-62\%; Table 3). In all breeds, the herd effect on C6:0, C14:1, and C16:1 was very low, whereas the effect on C16:0 was highest. Apart from this, a tendency existed for greater herd effects for C18 unsaturated FA.

\section{DISCUSSION}

\section{Samples}

As a part of the overall experimental sampling strategy, primarily milk from cows in midlactation was sam- pled in an attempt to minimize the animal variation in milk fat content and FA profile, because FA composition and desaturase indices mainly change in the early stage of lactation (Karijord et al., 1982; Palmquist et al., 1993; Kgwatalala et al., 2009). Likewise, seasonal variation, which otherwise can be pronounced (Lock and Garnsworthy, 2003; Thorsdottir et al., 2004), should be minimal due to sampling during the indoor season. Furthermore, by only including conventional herds, potential management differences between conventional and organic herds could be avoided (Ellis et al., 2006).

\section{Milk Fat Composition and Effect of Breed}

The effect of genetic background on FA composition leads to distinct FA signatures in individual breeds. Additionally, different management practices and feeding traditions in different countries could affect the difference in the FA profiles among breeds. Generally, DJ cows had higher fat and protein contents, but lower milk yield compared with DH cows, in particular. However, it should be kept in mind that only morning milk was collected in this study. Milk composition and yield is dependent on time interval since last milking, which may lead to differences between morning and afternoon milkings (Friggens and Rasmussen, 2001). In line with other studies, higher levels of short- and, to some extent, medium-chain FA (C6:0-C12:0) and lower levels of unsaturated FA were found in DJ compared with DH (Hermansen and Lund, 1990; White et al., 2001; Larsen et al., 2012). This breed difference is most likely a result of genetic background and, thus, independent of diet (Beaulieu and Palmquist, 1995). Here, C6:0 to C12:0 were 8 and $13 \%$ higher in DJ compared with $\mathrm{DH}$ and SR, respectively. The higher levels of C6:0 to C12:0 could suggest a higher de novo synthesis in DJ, although a negative genetic correlation between fat percentage and unsaturated C18 FA (Stoop et al., 2008) also implies that selection for increased fat percentage could be the underlying cause driving the distinct FA profile in DJ. Results of the OPLS-DA analysis (Figure 1) showed that all FA contributed significantly to the model and were, thus, all dependent on breed. Although the total content of C6:0 to C14:0 showed only limited variation among breeds, variation in the distribution of these FA was an important part of the breed differences according to the OPLS-DA analysis.

Apart from the individual FA, the breed effect on the different desaturase indices was also pronounced. The C14 index was lowest for DJ and highest for SR, indicating a lower genuine desaturase activity in DJ. The C14 index should be a good desaturase measure, because C14:0 derives almost solely from the de novo 


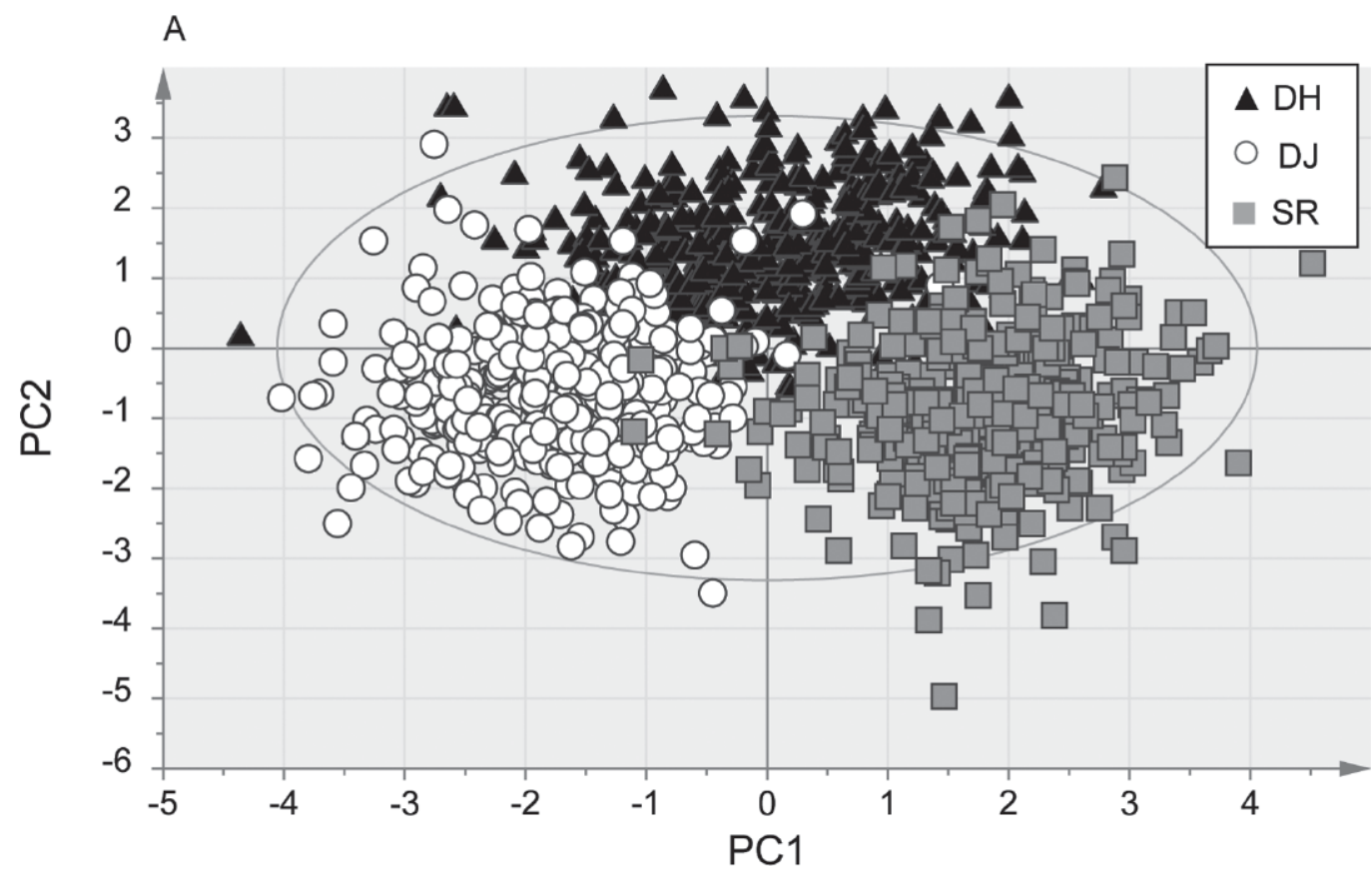

B

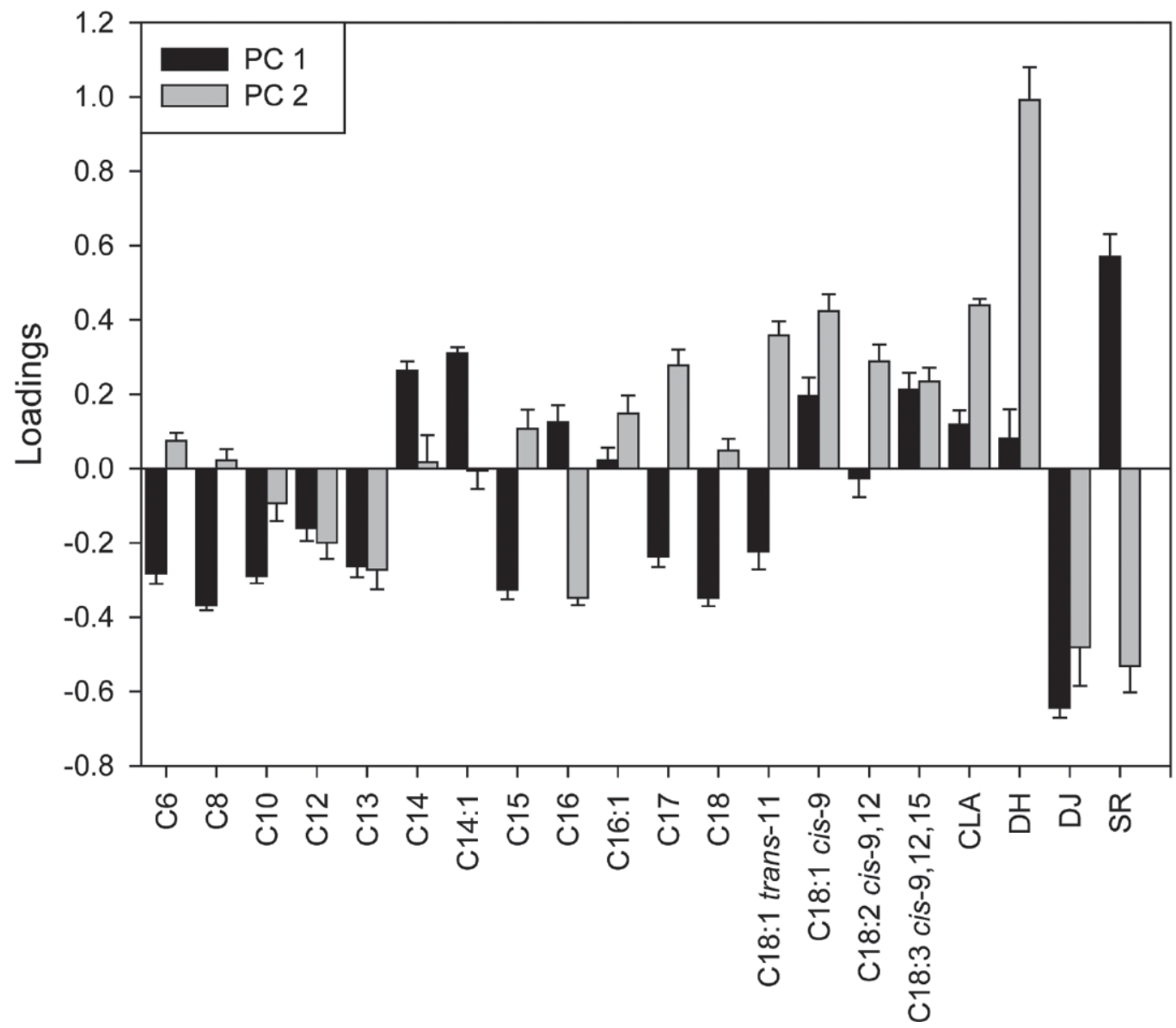

Figure 1. Orthogonal partial least squares discriminant analysis (OPLS-DA) for the 3 breeds: (A) OPLS-DA score plot for the first 2 principal components (PC) based on individual FA $(\mathrm{n}=1,298)$ in Danish Holstein-Friesians (DH), Danish Jerseys (DJ), and Swedish Reds (SR); (B) corresponding loadings for the first 2 PC. CLA = conjugated linoleic acid. Error bars show $95 \%$ confidence intervals for loadings. 

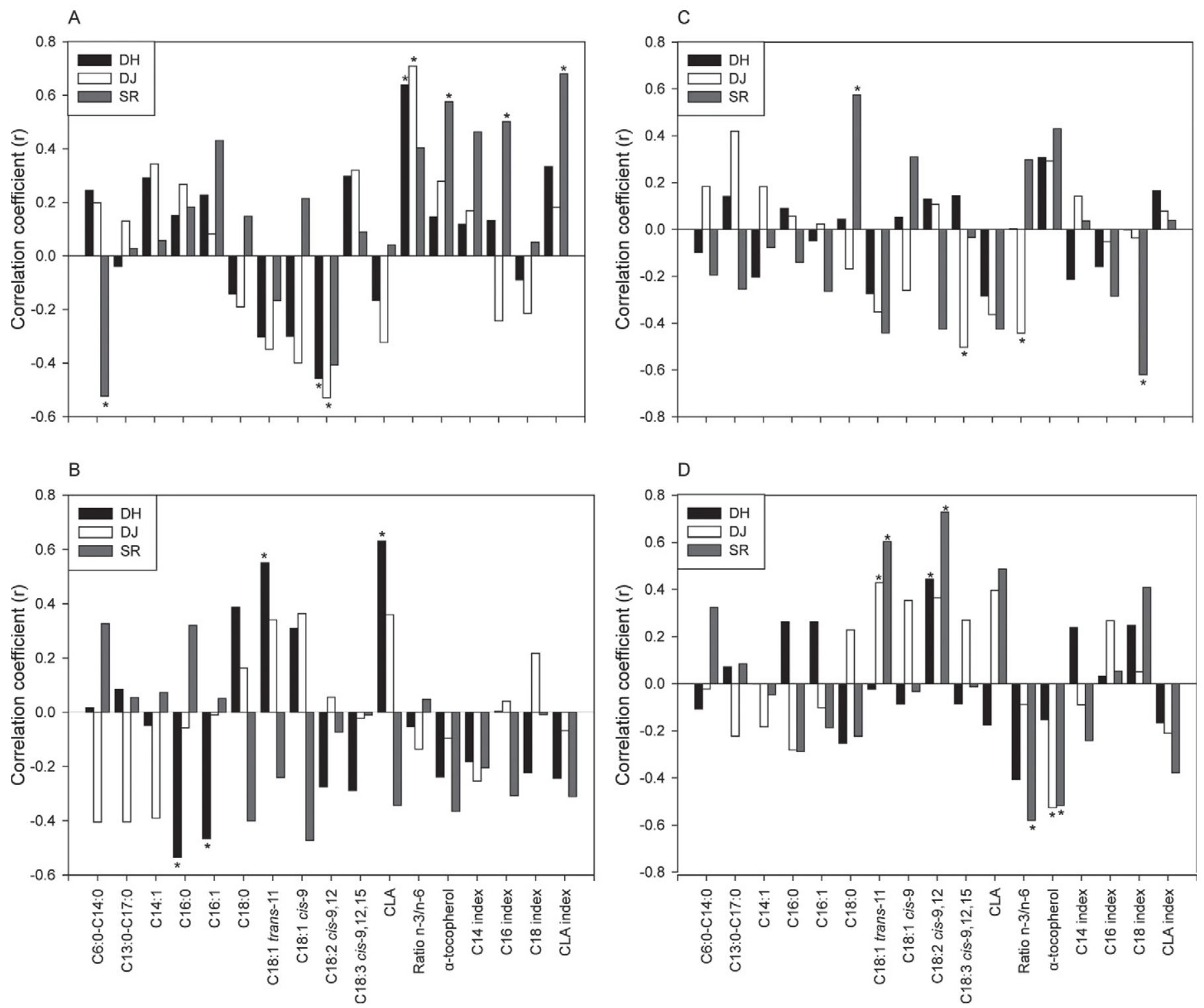

Figure 2. Pearson correlation coefficient (r) between feed categories and individual FA, n-3:n- 6 ratio, $\alpha$-tocopherol, and 4 different desaturase indices in Danish Holstein-Friesians (DH), Danish Jerseys (DJ), and Swedish Reds (SR): (A) grass products, (B) maize silage, (C) grain, and (D) concentrate. Significant correlations $(P<0.05)$ are marked with an asterisk $(*)$. CLA = conjugated linoleic acid.

synthesis within the mammary gland and, thus, C14:1 should purely be synthesized in the gland (Peterson et al., 2002). The observed difference between DH and DJ is in accordance with other studies (DePeters et al., 1995; Carroll et al., 2006). In contrast, other desaturase indices can be less indicative of actual mammary activity of $\Delta^{9}$-desaturase, because product and substrate can be derived from various sources (Lock and Garnsworthy, 2003). Differences between DH and DJ in other desaturase indices varied according to the difference in C14 index. However, differences between desaturase indices in SR and DH seemed to be dependent on the breedspecific FA composition. Thus, the C16 index was lower and the CLA index was much higher in SR compared with $\mathrm{DH}$, which was accompanied by higher content of C16:0 and lower content of C18:1 trans-11, respectively, and these differences in substrate availability may have led to different degrees of desaturation. The C18 index of SR and DH was almost equal and probably due to higher amounts of feed-derived C18:1 cis-9 in DH.

\section{Herd Effects on Individual FA}

The herd effect reflects difference in feeding regimens as well as other management differences among herds. The relatively low herd effect for short-chain FA in- 
Table 3. The proportion of total variance explained by herd variance for individual FA within Danish Holstein-Friesians (DH), Danish Jerseys (DJ), and Swedish Reds (SR)

\begin{tabular}{|c|c|c|c|}
\hline FA & DH & DJ & SR \\
\hline C6:0 & 12.46 & 12.72 & 8.96 \\
\hline C8:0 & 15.67 & 23.69 & 19.65 \\
\hline C10:0 & 16.66 & 28.89 & 31.88 \\
\hline C12:0 & 16.78 & 32.24 & 40.94 \\
\hline C13:0 & 15.76 & 26.52 & 35.57 \\
\hline C14:0 & 25.98 & 25.80 & 39.10 \\
\hline C14:1 & 6.93 & 13.99 & 9.33 \\
\hline C15:0 & 24.62 & 36.51 & 32.80 \\
\hline C16:0 & 25.39 & 61.92 & 52.59 \\
\hline C16:1 & 4.10 & 15.10 & 14.65 \\
\hline C17:0 & 4.22 & 25.43 & 35.52 \\
\hline C18:0 & 19.73 & 39.92 & 32.89 \\
\hline C18.1 cis-9 & 20.66 & 30.33 & 37.33 \\
\hline C18.1 trans-11 & 16.99 & 37.23 & 48.31 \\
\hline C18.2 cis-9,12 & 23.61 & 52.66 & 40.29 \\
\hline C18:2 cis-9,trans-11 & 13.74 & 38.53 & 46.36 \\
\hline C18.3 cis- $9,12,15$ & 25.22 & 47.07 & 41.03 \\
\hline Ratio n-3:n- $6^{1}$ & 35.09 & 78.75 & 43.39 \\
\hline C14 index ${ }^{2}$ & 0.00 & 5.82 & 3.70 \\
\hline C16 index ${ }^{3}$ & 0.00 & 4.02 & 3.22 \\
\hline C18 index ${ }^{4}$ & 7.57 & 14.09 & 7.43 \\
\hline CLA index ${ }^{5}$ & 2.64 & 6.32 & 12.56 \\
\hline$\alpha$-Tocopherol & 40.53 & 21.64 & 17.71 \\
\hline
\end{tabular}

${ }^{1}$ Ratio n-3:n-6 $=(\mathrm{C} 18: 3$ cis-9,12,15/C18:2 cis-9,12) $\times 100$.

${ }^{2} \mathrm{C} 14$ index $=\mathrm{C} 14: 1 /(\mathrm{C} 14: 1+\mathrm{C} 14: 0) \times 100$.

${ }^{3} \mathrm{C} 16$ index $=\mathrm{C} 16: 1 /(\mathrm{C} 16: 1+\mathrm{C} 16: 0) \times 100$.

${ }^{4} \mathrm{C} 18$ index $=\mathrm{C} 18: 1$ cis-9/(C18:1 cis-9 $\left.+\mathrm{C} 18: 0\right) \times 100$.

${ }^{5}$ Conjugated linoleic acid $(\mathrm{CLA})$ index $=\mathrm{C} 18: 2$ cis-9, trans-11/(CLA cis-9,trans-11 + C18:1 trans-11) $\times 100$.

dicates that the de novo synthesis to a large extent is genetically regulated. The common origin of these FA is also reflected in the strong correlation between these FA within breed (data not shown). The low herd effect for C6:0, C14:1, and C16:1 has also been documented in other studies (Karijord et al., 1982; Heck et al., 2012). The low variance for C14:1 and C16:1 strongly suggests that the desaturase activity underlying these FA, to a large extent, is genetically regulated, as also reflected in the overall low herd variances for the different desaturase indices. This is further supported by a significant effect of a mutation within the stearoyl-CoA desaturase 1 gene $(S C D 1)$ that seems to regulate a large part of the genetic variation in relation to unsaturation of milk FA (Schennink et al., 2007). In contrast, the large herd effect on C16:0 clearly reflects the fact that different management practices (including feed) strongly affect the level of C16:0 in different herds. Generally, $\mathrm{DH}$ cows respond well to feeding experiments, and the lower herd effect of $\mathrm{DH}$ was a bit unexpected, as the feed composition data showed similar variance for $\mathrm{DH}$ and DJ (Table 1).

In this study, all cows were placed indoors, and the effect of herd-specific feed supplies was evaluated through broad feed categories. In Denmark, the diets contained a higher proportion of maize silage, whereas a stronger tradition toward grass products and grain feeding was evident in Sweden. The proportion of forage as the sum of grass and maize silage varied from 30 to $76 \%$, but was, in general, lower in Sweden, where a higher level of grain was evident. An overall higher variance in the feed among herds in Sweden was reflected in stronger correlations between SR and the feed categories when compared with DJ and DH. A closer examination of the feed data showed strong negative correlations between grass and maize silage ( $\mathrm{r}$ values $=-0.63$ and -0.72 ), as well as between grain and other concentrate ( $\mathrm{r}$ values $=-0.69$ and -0.78$)$ for DJ as well as SR. For DH, these feed data were not correlated, suggesting that the pattern in feed composition was of a more random nature. Generally, the underlying reason for the breed differences is, thus, related to feeding and management traditions.

\section{Feed Effects on $\alpha$-Tocopherol and FA Composition}

The interplay between the content and composition of fat in feed and the composition of milk fat is rather complex, with multiple effects on the FA composition depending on, for example, level and choice of feed source and on forage-to-concentrate ratio. Generally, the content of SFA in milk is high, but increasing the addition of fat to the diet reduces the de novo synthesis and, thus, the content of saturated short- and mediumchain FA in milk fat (Grummer, 1991). Due to rumen hydrogenation, the transfer of unsaturated FA from feed to milk is relatively low (Jenkins and McGuire, 2006). Thus, the ability to predict the content of individual FA from the composition of dietary fat varies among FA (Hermansen, 1995). Within breeds, the de novo-synthesized FA were generally highly positively correlated with each other and negatively correlated with C16:0 and C18 FA (see also Karijord et al., 1982). Likewise, C14:1 and C16:1 were shown to be correlated in SR (correlation coefficient of $65 \%$ ). This pattern clearly reflects the common origin of different FA based on the de novo-synthesized FA, the feed-derived FA, and those being primarily regulated by the desaturase activity (C14:1 and C16:1).

Overall, the feed differences among herds within breeds were reflected in several significant correlations between herd means and the specific feed categories. The negative correlation between the proportion of grass products to the content of C6:0 to C14:0 in milk fat from SR could be related to reduced de novo synthesis of FA, when grass products high in C18 FA are the primary fat source (Slots et al., 2009). In contrast, the lack of such a correlation in milk fat from DH and DJ was most likely due to a much lower amount of grass 
products as well as a lower variation in these proportions among herds. These differences could also explain that $\alpha$-tocopherol was only positively correlated with grass products for SR. This positive association between the level of $\alpha$-tocopherol and the level of grass in the diet has also been established in earlier studies (Havemose et al., 2004; Slots et al., 2009). Overall, milk from cows fed pasture or grass silage contains higher amounts of antioxidants than, for example, maize-based diets, which is important for the oxidative stability of milk and dairy products. However, natural $\alpha$-tocopherol is also supposed to affect the composition of Swedish milk to a greater extent than the Danish milk, as Swedish dairy farmers use mineral mixtures (Larsen et al., 2010) rather than vitamin-mineral mixtures, which are used by Danish dairy farmers (Slots et al., 2009). Furthermore, the content of C18:2n- 6 was significantly, negatively correlated with the intake of grass products and resulted in a correlated response for the n-3:n-6 ratio in DH and DJ. This is due to the low level (less than $10 \%$ ) of C18:2n-6 in grass silage (Sejrsen et al., 2007) and is in accordance with results obtained by Slots et al. (2009).

The amount of maize silage in feed was only related to milk fat composition of $\mathrm{DH}$, which also had the highest maize silage proportions. The contents of C16:0 and C16:1 in milk fat were negatively correlated, whereas the contents of C18:1 trans-11 and CLA cis-9,trans-11 were positively correlated. This pattern was mainly associated with maize silage being a significant source of $\mathrm{C} 18: 2 \mathrm{n}-6$, which is hydrogenated to C18:1 trans-11 (Slots et al., 2009). The beneficial effect of pasturebased diets on, particularly, CLA is clear (Peterson et al., 2002), but as no association with grass products was observed, a positive correlation between maize and CLA cis-9,trans-11 in SR was shown. Because CLA is formed as an intermediate in the rumen via biohydrogenation of $\mathrm{C} 18: 2 \mathrm{n}-6$, of which high levels are found in maize, this might explain the positive correlation. Furthermore, the major source of CLA does not stem from biohydrogenation but from endogenous desaturation of C18:1 trans-11 (Griinari et al., 2000; Peterson et al., 2002).

The dietary effect from the nonforage feed categories on FA composition was primarily related to C18 FA. Generally, a high grain intake depresses milk fat percentage, and decreases the amount of short-chain FA, whereas the amount of C18 FA increases (Jenkins and McGuire, 2006). Swedish Red cows were, in general, fed grain-rich diets, which resulted in a significant, positive correlation with the content of C18:0 in milk fat. In DJ, a high level of grain resulted in a low level of C18:3n-3, which was also reflected in a negative correlation with the n-3:n-6 ratio. This may be due to high starch con- tent in grains, which could create more favorable conditions for rumen biohydrogenation. This could explain the effect on C18:0 and, to some extent, maybe also the negative correlation between grains and C18:3n-3 observed for DJ. In contrast to grain proportions, the amount of concentrate was positively correlated with the content of C18:1 trans-11 in milk fat from DJ and SR and C18:2n-6 for SR and negatively correlated with the $\alpha$-tocopherol in milk from DJ and SR. In the Danish breeds, concentrate was to a large extent related to rapeseed.

\section{CONCLUSIONS}

In this study, we examined the FA composition in 3 Scandinavian dairy breeds and revealed distinct FA profiles among these breeds. Furthermore, based on broad feed categories, we were able to pinpoint significant associations with individual FA despite herds being selected randomly and, thus, representing common feeding practice within country or breed. The dietary effect on FA composition is clear, but the experimental design of our study, and the low difference in feed supplementation from different herds minimized the ability to directly associate feed categories with FA composition. In spite of these constraints, the differences in feeding regimens among herds resulted in dietary responses affecting the milk fat composition significantly. Furthermore, the differences in the proportion of variation explained by herd between individual FA suggest that environmental variation affects individual FA differently, based on both breed and source of origin.

\section{ACKNOWLEDGMENTS}

The present work was supported by grants from Arla Foods amba (Viby J, Denmark), The Danish Cattle Federation (Aarhus, Denmark), the Danish Strategic Research Council (Copenhagen, Denmark), and Aarhus University (Tjele, Denmark). The Danish sampling and analysis team at the Danish-Swedish Milk Genomics Initiative (Tjele, Denmark) is gratefully acknowledged for excellent technical assistance, as well as Camilla Bjerg Kristensen, Department of Food Science, Aarhus University, Denmark, for her expertise in FA analyses.

\section{REFERENCES}

Albert, C. M., K. Oh, W. Whang, J. E. Manson, C. U. Chae, M. J. Stampfer, W. C. Willett, and F. B. Hu. 2005. Dietary $\alpha$-linolenic acid intake and risk of sudden cardiac death and coronary heart disease. Circulation 112:3232-3238.

Beaulieu, A. D., and D. L. Palmquist. 1995. Differential effects of high fat diets on fatty acid composition in milk of Jersey and Holstein cows. J. Dairy Sci. 78:1336-1344. 
Butler, G., J. H. Nielsen, T. Slots, C. Seal, M. D. Eyre, R. Sanderson, and C. Leifert. 2008. Fatty acid and fat-soluble antioxidant concentrations in milk from high- and low-input conventional and organic systems: Seasonal variation. J. Sci. Food Agric. 88:1431-1441.

Carroll, S. M., E. J. DePeters, S. J. Taylor, M. Rosenberg, H. Perez-Monti, and V. A. Capps. 2006. Milk composition of Holstein, Jersey, and Brown Swiss cows in response to increasing levels of dietary fat. Anim. Feed Sci. Technol. 131:451-473.

DePeters, E. J., J. F. Medrano, and B. A. Reed. 1995. Fatty acid composition of milk fat from three breeds of dairy cattle. Can. J. Anim. Sci. 75:267-269.

Djoussé, L., D. K. Arnett, J. J. Carr, J. H. Eckfeldt, P. N. Hopkins, M. A. Province, and R. C. Ellison. 2005. Dietary linolenic acid is inversely associated with calcified atherosclerotic plaque in the coronary arteries. Circulation 111:2921-2926.

Doreau, M., and A. Ferlay. 1994. Digestion and utilisation of fatty acids by ruminants. Anim. Feed Sci. Technol. 45:379-396.

Ellis, K. A., G. Innocent, D. Grove-White, P. Cripps, W. G. McLean, C. V. Howard, and M. Mihm. 2006. Comparing the fatty acid composition of organic and conventional milk. J. Dairy Sci. 89:19381950.

Friggens, N. C., and M. D. Rasmussen. 2001. Milk quality assessment in automatic milking systems: Accounting for the effects of variable intervals between milkings on milk composition. Livest. Prod. Sci. $73: 45-54$.

German, J. B., and C. J. Dillard. 2006. Composition, structure and absorption of milk lipids: A source of energy, fat-soluble nutrients and bioactive molecules. Crit. Rev. Food Sci. Nutr. 46:57-92.

Givens, D. I. 2010. Milk and meat in our diet: Good or bad for health? Animal 4:1941-1952.

Griinari, J. M., B. A. Corl, S. H. Lacy, P. Y. Chouinard, K. V. V. Nurmela, and D. E. Bauman. 2000. Conjugated linoleic acid is synthesized endogenously in lactating dairy cows by delta-9-desaturase. J. Nutr. 130:2285-2291.

Grummer, R. R. 1991. Effect of feed on the composition of milk fat. J. Dairy Sci. 74:3244-3257.

Havemose, M. S., M. R. Weisbjerg, W. L. P. Bredie, and J. H. Nielsen. 2004. Influence of feeding different types of roughage on the oxidative stability of milk. Int. Dairy J. 14:563-570.

Heck, J. M., H. J. van Valenberg, H. Bovenhuis, J. Dijkstra, and T. C. van Hooijdonk. 2012. Characterization of milk fatty acids based on genetic and herd parameters. J. Dairy Res. 79:39-46.

Hermansen, J. E. 1995. Prediction of milk fatty acid profile in dairy cows fed dietary fat differing in fatty acid composition. J. Dairy Sci. 78:872-879.

Hermansen, J. E., and P. Lund. 1990. Fatty acid composition and milk quality related to feeding Ca-saponified palm acid oil to different breeds of dairy cows. J. Dairy Res. 57:23-31.

Jenkins, T. C., and M. A. McGuire. 2006. Major advances in nutrition: Impact on milk composition. J. Dairy Sci. 89:1302-1310.

Karijord, Ø., N. Standal, and O. Syrstad. 1982. Sources of variation in composition of milk fat. Z. Tierz. Züchtungsbiol. 99:81-93.

Kgwatalala, P. M., E. M. Ibeagha-Awemu, A. F. Mustafa, and X. Zhao. 2009. Stearoyl-CoA desaturase 1 genotype and stage of lactation influences milk fatty acid composition of Canadian Holstein cows. Anim. Genet. 40:609-615.

Larsen, M. K., L. Hymøller, D. B. Brask-Pedersen, and M. R. Weisbjerg. 2012. Milk fatty acid composition and production performance of Danish Holstein and Danish Jersey cows fed different amount of linseed and rapeseed. J. Dairy Sci. 95:3569-3678.
Larsen, M. K., J. H. Nielsen, G. Butler, C. Leifert, T. Slots, G. H. Kristiansen, and A. H. Gustafsson. 2010. Milk quality as affected by feeding regimens in a country with climatic variation. J. Dairy Sci. 93:2863-2873.

Larsen, T., M. K. Larsen, and N. C. Friggens. 2011. Enzymatic and fluorometric determination of triacylglycerols in cow milk and other opaque matrices. Food Chem. 125:1110-1115.

Lawless, F., C. Stanton, P. L'Escop, R. Devery, P. Dillon, and J. J. Murphy. 1999. Influence of breed on bovine milk cis-9, trans11-conjugated linoleic acid content. Livest. Prod. Sci. 62:43-49.

Lock, A. L., and P. C. Garnsworthy. 2003. Seasonal variation in milk conjugated linoleic acid and $\Delta^{9}$-desaturase activity in dairy cows. Livest. Prod. Sci. 79:47-59.

Maijala, K. 2000. Cow milk and human development and well-being. Livest. Prod. Sci. 65:1-18.

Mensink, R. P., P. L. Zock, A. D. Kester, and M. B. Katan. 2003. Effects of dietary fatty acids and carbohydrates on the ratio of serum total to HDL cholesterol and on serum lipids and apolipoproteins: A meta-analysis of 60 controlled trials. Am. J. Clin. Nutr. 77:1146-1155.

Palmquist, D. L., A. D. Beaulieu, and D. M. Barbano. 1993. Feed and animal factors influencing milk fat composition. J. Dairy Sci. 76:1753-1771.

Peterson, D. G., J. A. Kelsey, and D. E. Bauman. 2002. Analysis of variation in cis-9, trans-11 conjugated linoleic acid (CLA) in milk fat of dairy cows. J. Dairy Sci. 85:2164-2172.

Schennink, A., W. M. Stoop, M. H. P. W. Visker, J. M. L. Heck, H. Bovenhuis, J. J. van der Poel, H. J. F. van Valenberg, and J. A. M. van Arendonk. 2007. DGAT1 underlies large genetic variation in milk-fat composition of dairy cows. Anim. Genet. 38:467-473.

Schennink, A., W. M. Stoop, M. H. P. W. Visker, J. J. van der Poel, H. Bovenhuis, and J. A. M. van Arendonk. 2009. Short communication: Genome-wide scan for bovine milk-fat composition. II. Quantitative trait loci for long-chain fatty acids. J. Dairy Sci. 92:4676-4682.

Sejrsen, K., T. Bjorn, and S. K. Jensen. 2007. Prospects of obtaining favourable fatty acid composition of cows milk by feeding. J. Anim. Feed Sci. 16:7-20.

Simopoulos, A. P. 2002. The importance of the ratio of omega-6/omega-3 essential fatty acids. Biomed. Pharmacother. 56:365-379.

Slots, T., G. Butler, C. Leifert, T. Kristensen, L. H. Skibsted, and J. H. Nielsen. 2009. Potentials to differentiate milk composition by different feeding strategies. J. Dairy Sci. 92:2057-2066.

Stoop, W. M., A. Schennink, M. H. P. W. Visker, E. Mullaart, J. A. M. van Arendonk, and H. Bovenhuis. 2009. Genome-wide scan for bovine milk-fat composition. I. Quantitative trait loci for short- and medium-chain fatty acids. J. Dairy Sci. 92:4664-4675.

Stoop, W. M., J. A. M. van Arendonk, J. M. L. Heck, H. J. F. van Valenberg, and H. Bovenhuis. 2008. Genetic parameters for major milk fatty acids and milk production traits of Dutch HolsteinFriesians. J. Dairy Sci. 91:385-394.

Thorsdottir, I., J. Hill, and A. Ramel. 2004. Short communication: Seasonal variation in cis-9, trans-11 conjugated linoleic acid content in milk fat from Nordic countries. J. Dairy Sci. 87:2800-2802.

White, S. L., J. A. Bertrand, M. R. Wade, S. P. Washburn, J. Green, and T. C. Jenkins. 2001. Comparison of fatty acid content of milk from Jersey and Holstein cows consuming pasture or a total mixed ration. J. Dairy Sci. 84:2295-2301. 